\title{
Avaliação do Perfil Microbiológico de Bebidas Lácteas Sabor Morango Comercializadas Na Cidade de Limoeiro do Norte- CE
}

\section{Zulene Lima De Oliveira (I), Auriana De Assis Regis (I), Pahlevi} Augusto De Souza (I), Elisabeth Mariano Batista (I), Hildenir Lima De Freitas (I), Raimunda Valdenice Da Silva Freitas (I), Hirllen Nara Bessa Rodruigues (I), Poliana Brito De Sousa (II,I)

(I) IFCE - Instituto Federal do Ceará - Campus Limoeiro do Norte (Rua Estevão Remigio, N 1145, Centro, Limoeiro do Norte - CE.), (II) IFPI - Campus Urucui - Instituto Federal do Piauí -

Campus Uruçuí (Rodovia PI 247 km 7 s/n, zona rural, Portal dos Cerrados, Uruçuí, RI)

\section{Resumo}

O soro lácteo é um subproduto alimentício oriundo das indústrias queijeiras que é produzido em grande escala no Brasil. Por ser uma fonte rica em proteínas e minerais vêm sendo utilizado pela indústria em geral.

Entretanto, é na de alimentos que esse subproduto é mais empregado e dentre as várias formas de aproveitamento destaca-se sua utilização na elaboração de bebidas lácteas. A bebida láctea pode ser definida como o produto resultante da mistura de leite e soro e/ ou leite reconstituído desde que a base láctea represente pelo menos $51 \%$. É um tipo de leite fermentado que vem se destacando como substituto do iogurte. Tendo em vista a elevada produção de soro lácteo e seu valor nutricional, objetivou-se com o presente trabalho avaliar o perfil microbiológico de bebidas lácteas sabor morango comercializado na cidade de Limoeiro do Norte-CE. Foram adquiridas no comércio local três marcas diferentes de bebida láctea sabor morango. As amostras foram acondicionadas em isopor com gelo e encaminhadas ao laboratório de microbiologia de alimentos do Instituto Federal do Ceará - IFCE, Campus Limoeiro do Norte. Realizou-se em triplicata a determinação do $\mathrm{NMP} / \mathrm{mL}$ de Coliformes totais, termotolerantes e pesquisa de Escherichia coli. Para a realização das análises seguiram-se

\footnotetext{
Referência:

Zulene Lima De Oliveira, Auriana De Assis Regis, Pahlevi Augusto De Souza, Elisabeth Mariano Batista, Hildenir Lima De Freitas, Raimunda Valdenice Da Silva Freitas, Hirllen Nara Bessa Rodruigues, Poliana Brito De Sousa. Avaliação do Perfil Microbiológico de Bebidas Lácteas Sabor Morango Comercializadas Na Cidade de Limoeiro do Norte- Ce. In: Anais do $12^{\circ}$ Congresso Latinoamericano de Microbiologia e Higiene de Alimentos - MICROAL 2014 [= Blucher Food Science Proceedings, num.1, vol.1]. São Paulo: Editora Blucher, 2014. DOI $10.5151 /$ foodsci-microal-198
} 
as diretrizes gerais da American Public Health Association - APHA. As três marcas de bebidas lácteas analisadas encontraram-se dentro dos padrões microbiológicos estabelecidos pela legislação vigente ( $\mathrm{RDC}{ }^{\circ} 12$ de 02 de janeiro de 2001), pois, os resultados da contagem de coliformes totais e termotolerantes apresentaram valor

Palavras-Chave: produto lacteo, contaminação, soro de leite Agência de Fomento: 